\title{
Dinámica fluvial, propiedad de la tierra y conservación del paisaje de ribera en el entorno de Aranjuez (Madrid, Toledo)
}

\section{Fluvial dynamic, land property and fluvial landscape conservation in the area of Aranjuez (Madrid, Toledo)}

\author{
Pedro Molina Holgado* y Ana Belén Berrocal Menárguez**
}

\section{INTRODUCCIÓN}

Los paisajes fluviales han sido objeto de intensas presiones que han provocado una profunda modificación y alteración de sus estructuras naturales (Yon y Tendron, 1981). En Europa han experimentado una fuerte degradación y, en España, se estima que la desaparición de cauces naturales en el periodo 1987-2000 alcanzó un valor del 12\% (7.508 ha), sobre un total potencial de 2 millones de hectáreas, valor que representa un 4\% del territorio español. Esta disminución, en gran medida causada por el incremento de la superficie artificializada, supone además la degradación o desaparición de los paisajes fluviales asociados (González y Lastra, 2007).

Los efectos negativos de la modificación de los regímenes hidrológicos y de las características hidráulicas de los cursos han sido puestos de manifiesto en numerosos trabajos (Décamps et al., 1995 y 1998; Jannson et al., 2010; Johnson, 1998; Molina y Berrocal, 2006; Molina, Berrocal y Barrasa, 2012; Molina, Sanz y Mata, 2010; Petts et al., 1989; Poff et al., 2010; Nilsson et al., 2005,

\footnotetext{
*Departamento de Geografía, Universidad Autónoma de Madrid (pedro.molina@uam.es).

${ }^{* *}$ Departamento de Ordenación del Territorio, Urbanismo y Medio Ambiente, ETSI Caminos, Canales y Puertos. UPM (anabelen.berrocal@upm.es).
} 
2007; Poff y Zimerman, 2010). En España, la degradación del territorio fluvial está estrechamente relacionada con la alteración hidrológica de las cuencas hidrográficas, como también sucede en otras zonas de Europa o América del Norte, donde el $77 \%$ de los cursos fluviales están afectados por la regulación de las cuencas (Dynesius y Nilsson, 1994), aunque su incidencia territorial ha sido en general tardía, posterior a 1950.

Hasta la segunda mitad del siglo xx, la mayor parte de los espacios fluviales conservaron muchos de sus atributos originarios, siendo incluso el límite de la última frontera agrícola en las grandes llanuras del interior ibérico en áreas secas o semiáridas como el entorno de Aranjuez. La conservación de los paisajes ribereños con cierto grado de naturalidad estuvo vinculada, más que a su uso armónico y equilibrado, al riesgo evidente derivado de los periodos cíclicos de aguas altas extraordinarias. El control de las crecidas extraordinarias durante los años 70 y 80 del siglo xx y el desarrollo de numerosas intervenciones estructurales en los cauces, permitió la ocupación de las llanuras de inundación de ríos que, como el Tajo hasta su control, eran difíciles de vadear «por lo que exigía barca o puente para cruzarlo» y cuya intensa corriente les otorgaba «una importante capacidad energética, aprovechada por los numerosos molinos instalados en sus orilla» (Arroyo, 2006).

La dinámica de los espacios naturales y seminaturales localizados en las llanuras de inundación de los cursos de la cuenca del Tajo, en particular las de los ríos Tajo y Jarama en el entorno de Aranjuez, se caracteriza por la reducción continua y progresiva fragmentación de este tipo de espacios, de gran valor natural y paisajístico (Molina y Berrocal, 2006). En la primera década del siglo XXI, la superficie forestal ocupada en ambas planas aluviales representaba el 4,6\% de la existente en 1865, cifra que supone menos de un $2 \%$ de la superficie potencial de bosques de ribera en esta zona.

A diferencia de lo sucedido en otras cuencas, el territorio fluvial del valle del Tajo-Jarama en Aranjuez mantuvo una gran naturalidad hasta el último cuarto del siglo XIX, a pesar de ser un paisaje donde la huella humana sobre el territorio es tan intensa que difícilmente pueden disociarse los elementos naturales de los construidos (Berrocal y Molina, 2012). La consideración de este extenso ámbito como Real Sitio favoreció la conservación de un amplio espacio fluvial, de gran naturalidad hasta el inicio del proceso desamortizador que se desarrolló después de 1855. Desde esa fecha, especialmente con posterioridad a los años 70 del siglo xIX, comienza la intensa transformación del hasta entonces muy extenso Bosque de Aranjuez. Este es, en efecto, el primer paso notable en la modificación del paisaje que caracterizó este sector de la vega del Tajo durante la mayor parte de los siglos XVIII y XIX y que, 150 años des- 
pués, daría lugar al actual paisaje de la llanura aluvial: una vega intensamente ocupada, de elevada productividad agraria, casi un monocultivo de maíz con amplio desarrollo de variedades transgénicas, donde los espacios naturales (sotos, tarayales, madres viejas con vegetación palustre, prados, juncales, etc.) ocupan una posición marginal y residual. Estos rodales y doseles forestales poseen todavía, a pesar de su reducida extensión y compartimentación, gran importancia y valor en términos de diversidad ecológica, estética y paisajística, una característica propia de este tipo de medios (Alland, 1999, 2004; González del Tánago, 1999; Naiman et al., 1993).

$\mathrm{Si}$, en origen, la rotura de los espacios naturales y seminaturales de la llanura de inundación está claramente vinculada al proceso desamortizador, posteriormente, las pérdidas de estos ámbitos se deben, como en la mayor parte

\section{MAPA DE LOCALIZACIÓN DEL ÁREA DE ESTUDIO}

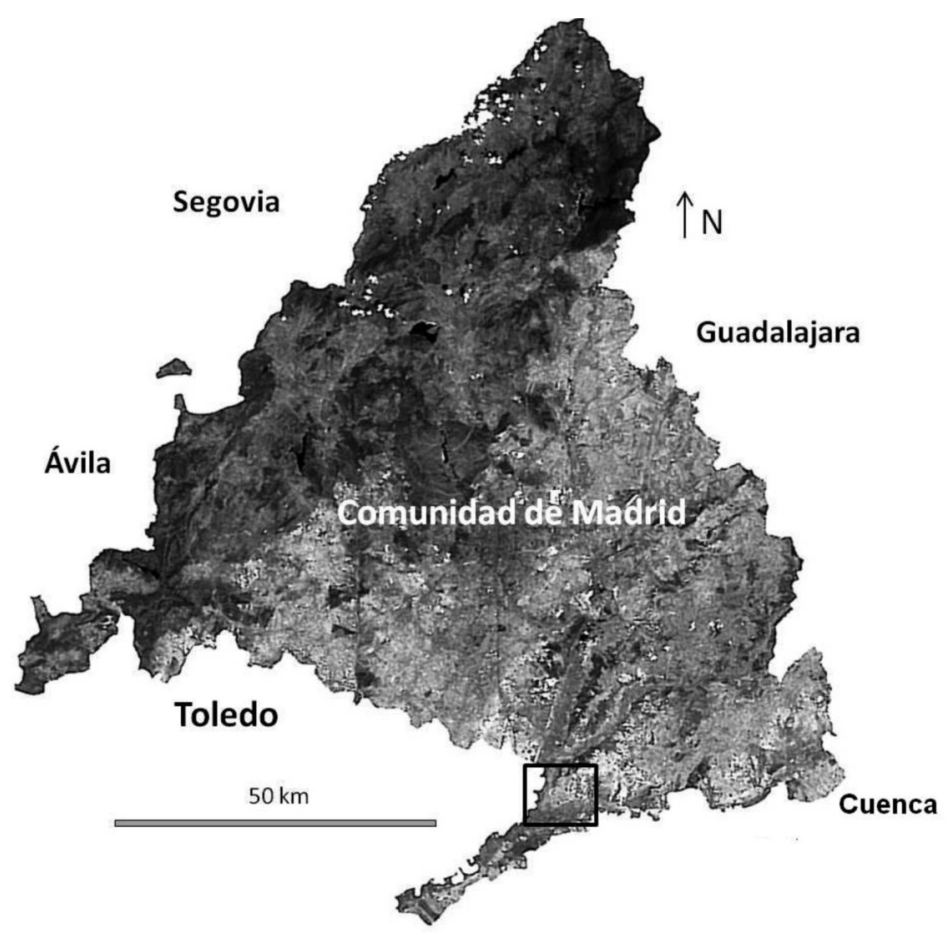

Fuente: elaboración propia. 
de los grandes ríos ibéricos, a la alteración hidrológica del sistema fluvial derivada de la construcción de presas en la cabecera y en algunas zonas medias de la cuenca.

\section{LOS ORÍGENES DEL REAL SITIO: LA CONSTRUCCIÓN DEL PAISAJE}

La ribera de Aranjuez es un espacio de antigua ocupación cuyo territorio estuvo estrechamente vinculado a la Orden de Santiago hasta el siglo XVI. Una parte sustancial de la vega del Tajo situada aguas arriba de la Junta de los Ríos -el ámbito donde este curso y el Jarama unen sus aguas-, estuvo integrada hasta entonces en la Encomienda de Oreja, tras la donación de este territorio hecha a la orden por Alfonso VIII en 1171 (González, 1975). El espacio que hoy coincide con la villa de Aranjuez y su entorno inmediato, aguas abajo del pago de Oreja, perteneció también a esta orden, aunque no se estructuró como una encomienda sino como una tenencia de la Mesa Maestral con jurisdicción propia ejercida por un «tenente». Esto mismo se observa en otras zonas próximas situadas en las vertientes del valle del Tajo a escasos kilómetros aguas arriba.

Las referencias más antiguas de las «visitas» de la Orden citan huertas, aceñas y un batán, elementos que atestiguan la vocación agraria de estas tierras. Existen citas de al menos tres huertas regadas con agua del Tajo en 1480 (De Miguel y Segura, 1998) y Álvarez de Quindós (1993 [1804]) señala también la existencia de aceñas, huertas y una azuda ya en el siglo XII. Las tierras más meridionales de la vega, próximas al núcleo de Aceca, estuvieron vinculadas a la Orden de Calatrava al menos desde el siglo XIII. Previamente, en este mismo espacio, Alfonso VI estableció en 1102 una puebla con 200 vecinos mozárabes sobre una fortaleza musulmana preexistente (Gónzález, 1975). Esta orden también poseía la Encomienda de Otos, sobre tierras que posteriormente integrarían, entre otros, los cuartes de Castillejos y La Flamenca.

El origen de la trama agraria de la vega, a pesar de su antigua ocupación, es más reciente: está vinculado a un minucioso programa de intervenciones que se prologa desde el siglo XVI hasta el siglo xx (Molina, Sanz y Mata, 2010), siendo fundamental la configuración de esta vega como Real Sitio y muy especialmente las labores e intervenciones llevadas a cabo durante los siglos XVI y XVIII. No en vano, el planteamiento originario de Aranjuez es fruto de un plan específico, iniciado en 1560, que se prolonga hasta la muerte de Felipe II, y concibe este territorio de acuerdo con la idea renacentista de organización del espacio (Luengo, 2008). Tras más de un siglo de inactividad, la monarquía borbónica, recién instaurada tras la Guerra de Sucesión, impulsa de nuevo el 
desarrollo de Aranjuez, explotando con acierto la potencialidad natural del fondo de valle: la singularidad de la vega del Tajo, de húmedo subsuelo, permitió a la nueva monarquía recrear en la seca meseta meridional un paisaje similar al de los grandes jardines centroeuropeos, característicos de los contextos palaciegos de la dinastía matriz. Todo ello a partir de lo construido en el siglo XVI, aunque con una comprensión espacial y una cosmogonía bien diferente a la de aquel siglo.

Aranjuez es, en definitiva, un paisaje construido sobre dos grandes visiones territoriales y morales, propias, respectivamente, de los siglos XVI y XVIII. En este último caso, puede considerarse quizás el remedo ibérico de los grandes jardines borbónicos de Francia. Fue construido en la ribera del Tajo, como señala Sanz Hernando (2008), aprovechando una excelente localización natural para su establecimiento debido a la confluencia de dos ríos, a la abundancia de agua, a la horizontalidad del terreno y a la riqueza del suelo.

El siglo XVIII es sin duda un momento crucial en la actual configuración del Real sitio, en particular el intervalo temporal coincidente con el reinado de Carlos III. Intervenciones y actuaciones notables, definitorias de la actual morfología de Aranjuez, como la construcción de los Jardines de El Príncipe, el trazado del Real Cortijo de San Isidro, la prolongación del Caz de Colmenar, la creación del Mar de la Cavina o la puesta en producción de la finca de La Flamenca - el antiguo «Campo Flamenco»— datan de esta época. Sobre este último espacio es de gran interés señalar lo que indica López y Malta (1868):

La ilustración del gran Carlos III no pudo tolerar más tiempo el sensible abandono de estas dilatadas campiñas, disponiendo entregarlas al cultivo por una Real órden de fecha 23 de setiembre de 1775, en el que se mando cercar sobre el Soto de Butron, unas doscientas fanegas de tierra para establecer el cultivo al estilo de Flandes, del cual provino el nombre de Flamenca á la casa de labor y tierras que la formaban [...]. Sus deseos se cumplieron, pues bien pronto estos campos antes yelmos se transformaron en productivos terrenos, formando cuadros por medio de calles y líneas de álamos negros y moreras, en los que primero se sembró trébol y alfalfa para mantener en invierno a la Real yeguada (...). Para regar la parte baja de este terreno se limpio el caz de las Aves, que estaba obstruido desde el desaguador de las Huelgas $[\ldots]$.

En los espacios ordenados del Real Sitio, mayoritariamente situados aguas arriba de la junta del Tajo-Jarama, desde su origen y hasta prácticamente el último cuarto del siglo XIX, los cultivos se organizaron sobre tranzones jalonados por una amplia red de paseos arbolados, diseñados con fines estéticos, cuidando con esmero la proporción y la perspectiva. La producción agrícola de estos espacios se organizaba atendiendo a los dictámenes reales, quedando 
totalmente ajena a las vicisitudes de una agricultura productiva (Aníbarro, 2010). La huerta y los frutales eran el uso preferente de estas tierras, articuladas en torno a la plaza de las Doce Calles, en los parajes de Legamarejo y Picotajo. Aguas abajo de la confluencia de los ríos —en la margen izquierda-, una estrecha y limitada franja irrigada por el Canal de las Aves ocupaba la primera terraza, replicando a muy pequeña escala y de manera considerablemente más simple la estructura de tranzones y paseos arbolados que caracteriza al tramo alto.

\section{LA ALTERACIÓN HIDROLÓGICA DEL SISTEMA TAJO-JARAMA Y SU IMPORTANCIA EN EL PAISAJE DE ARANJUEZ}

Las características hidrológicas e hidráulicas actuales de los ríos Tajo y Jarama han variado sustancialmente respecto a las específicas de estos cursos en régimen natural debido a la alteración del sistema fluvial. Las causas de esta profunda modificación se deben en gran medida a la construcción de presas en todos los cursos importantes y a la detracción de una parte significativa de sus caudales, principalmente desde el trasvase Tajo-Segura, como han señalado Molina y Berrocal (2006). A esta intensa alteración antrópica se suma además el descenso de las precipitaciones observada en toda la cuenca desde los primeros años de la década de 1960 (Gallego y Sánchez, 2006), tendencia que se agravará en el futuro en el centro de la península como han puesto de manifiesto recientemente Cañada, Galán y Fernández (2010). El descenso de las precipitaciones, especialmente notable en la cabecera del Tajo, se refleja en la disminución de los registros aforados en los embales del sistema Entrepeñas-Buendía (figura 2): el valor medio de la aportación en el periodo 1980$2009(765,5 \pm 60,2)$ representa sólo el $45 \%$ de la aportación registrada entre 1954 y $1980(1.391,7 \pm 358,4)$.

En 2000, el volumen de agua embalsada en la cuenca aguas arriba de la ciudad de Toledo (Estación $\left.\mathrm{n}^{\circ} 3.014\right)\left(3.843,11 \mathrm{hm}^{3}\right)$ superaba en un $18 \%$ a la aportación media anual en régimen natural de este aforo $\left(3.256,93 \mathrm{hm}^{3}\right)$, mientras que el volumen de embalse acumulado en Aranjuez, aguas abajo de la confluencia Tajo-Jarama en ese mismo periodo $\left(3.834,31 \mathrm{hm}^{3}\right)$, superaba en más de un $25 \%$ a la aportación natural. Como puede observarse en la figura 3 , hasta el inicio de la década de los años 50 del siglo xx, coincidiendo con la construcción de las grandes presas de Entrepeñas y Buendía, el volumen regulado suponía sólo el 3,9\% del total regulado en 2012, alcanzando ya en 1960 un valor del $72,8 \%$. 
FIGURA 2

EVOLUCIÓN DE LAS APORTACIONES EN EL AFORO DE ENTREPEÑAS-BUENDIA EN HM ${ }^{3}$

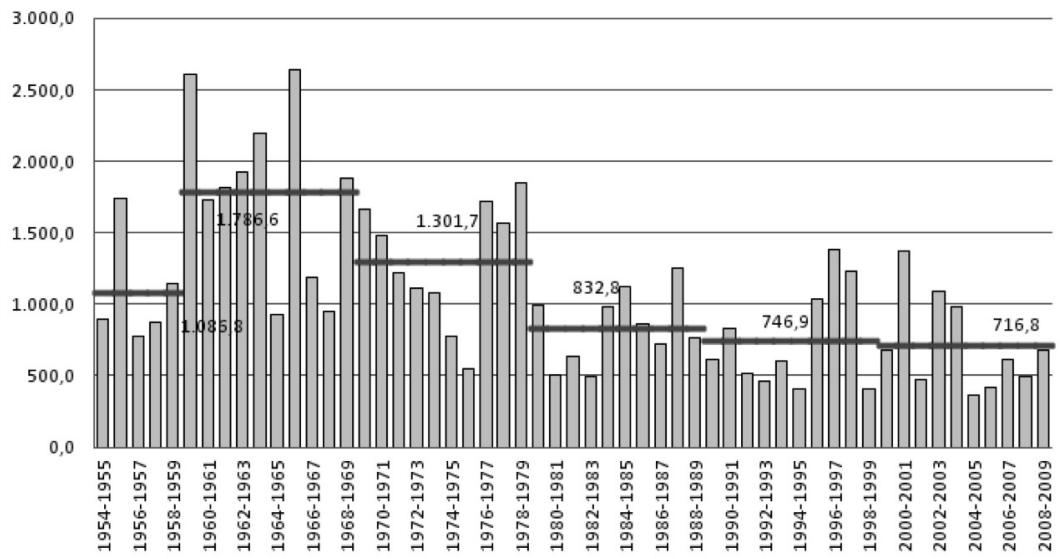

Nota: los datos numéricos indican el promedio en $\mathrm{hm}^{3}$ por décadas.

Fuente: elaboración propia a partir de datos aforados en los embalses del sistema Entrepeñas-Buendía.

FIGURA 3

VOLUMEN DE LOS EMBALSES CONSTRUIDOS EN LA CUENCA POR DÉCADAS (EJE PRIMARIO) Y VOLUMEN ACUMULADO (EJE SECUNDARIO)

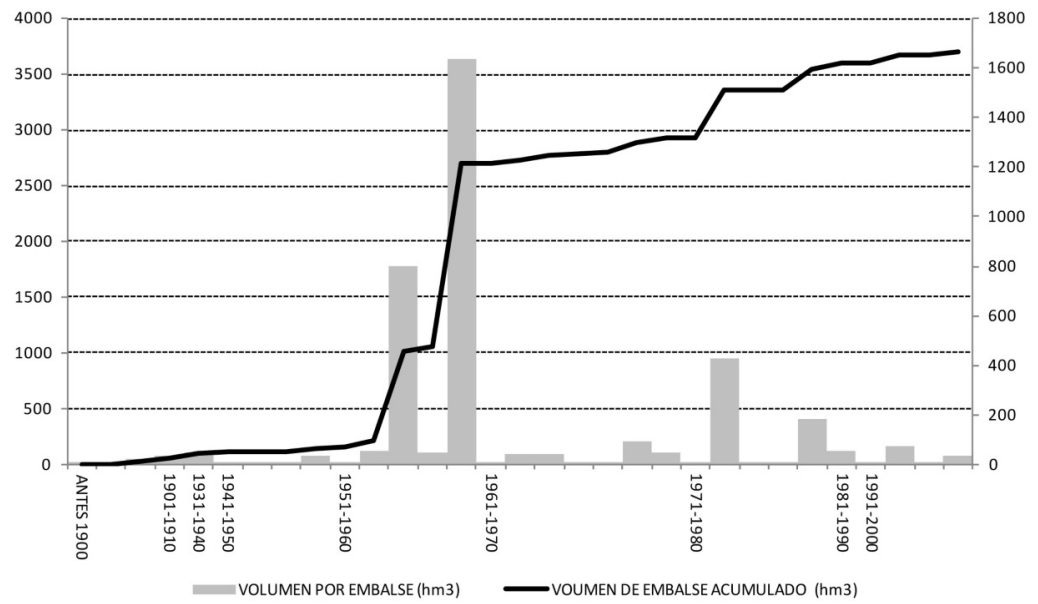

Fuente: elaboración propia a partir de datos aforados en los embalses del sistema Entrepeñas-Buendía. 
Globalmente, el tramo más alterado en términos hidrológicos de la ribera del Tajo en Aranjuez es el situado aguas arriba de la Junta de los Ríos. Esto se debe principalmente al impacto del trasvase Tajo-Segura: desde su entrada en servicio, la aportación anual del río Tajo ha experimentado un descenso del 48,8\%, pasando de $1.022 \mathrm{hm}^{3}$ en el año hidrológico 1979-1980 a $499 \mathrm{hm}^{3}$ en el año 1980-1981 y tan sólo 197,26 hm³ en 1994-1995, el registro mínimo histórico (figura 6). La media del periodo 1980-1981/2001-2002 (289,79 $\left.\mathrm{hm}^{3}\right)$, representa sólo el 25,87\% de la registrada entre 1920-1921/1979-1980 (1.120,04 hm³).

La relación existente entre las aportaciones del aforo de la estación de El Embocador $\left(n^{\circ} 3.258\right)$ y los caudales derivados por el trasvase Tajo-Segura (Estación $\mathrm{n}^{\circ}$ 3.402) durante el periodo de datos disponible (años hidrológicos 1978-1979/2002-2003) puede observarse en la figura 5, donde se muestran los resultados tras ajustar un modelo logarítmico para describir la citada relación $[y=-324,6 \ln (x)+2206,6 x]$.

Puede observarse que entre ambos valores existe una relación estadísticamente significativa (ANOVA $\mathrm{F}_{1}, 22=30,23 ; \mathrm{p}<0,005$ ) con un nivel de confianza del 95,0\%. El estadístico $\mathrm{R}^{2}$ indica que el modelo ajustado explica $57,88 \%$ de la variabilidad de las aportaciones anuales del aforo de El Embocador. El coeficiente de correlación indica una relación fuerte entre las variables $(-0,7608$; $\mathrm{p}<0,05 ; \mathrm{n}=23$ ).

La derivación resultante del trasvase es sin duda el impacto más acusado, aunque es preciso considerar además el efecto acumulado de las detracciones de los canales de riego de Estremera, Acequia Real del Tajo (Canal de Colmenar), Caz Chico y Canal de las Aves. Tomando datos de la única serie competa de los cinco canales que afectan al Tajo hasta Aranjuez (1978-1979/19992000), las detracciones del trasvase oscilan entre un valor mínimo porcentual del 11,5\% en 1980-1981, al inicio de su fase de explotación, y un máximo del $79 \%$ en $1999-2000$, siendo el valor medio del 55,4\%.

La incidencia de la regulación de la cabecera del río ha sido también notable en el caudal medio anual del Tajo aguas abajo de los embalses de Entrepeñas y Buendía: como puede observarse en la figura 6, elaborada con datos de las estaciones de aforo de Aranjuez (Estación $n^{\circ}$ 3.001) y El Embocador (Estación $n^{\circ}$ 3.258). La utilización conjunta de estas dos estaciones permite completar los datos del aforo de El Embocador, cuya serie se inicia en el año 1978-1979, y aunque existen algunas diferencias en los 6 registros coincidentes, no existen diferencias estadísticamente significativas entre los mismos ( $\mathrm{w}=22,5 ; \mathrm{p}=0,5211 ; \mathrm{n}=6)$ y la correlación entre los valores comunes es muy elevada $\left(r_{s}=0,867 ; p>0,05 ; n=6\right)$, quedando muy cerca del umbral de la significación $\left(r_{s}=0,886 ; p<0,05\right)$. 


\section{FIGURA 4}

EVOLUCIÓN DE LOS CAUDALES DERIVADOS (EN HM³) POR EL TRASVASE TAJO-SEGURA

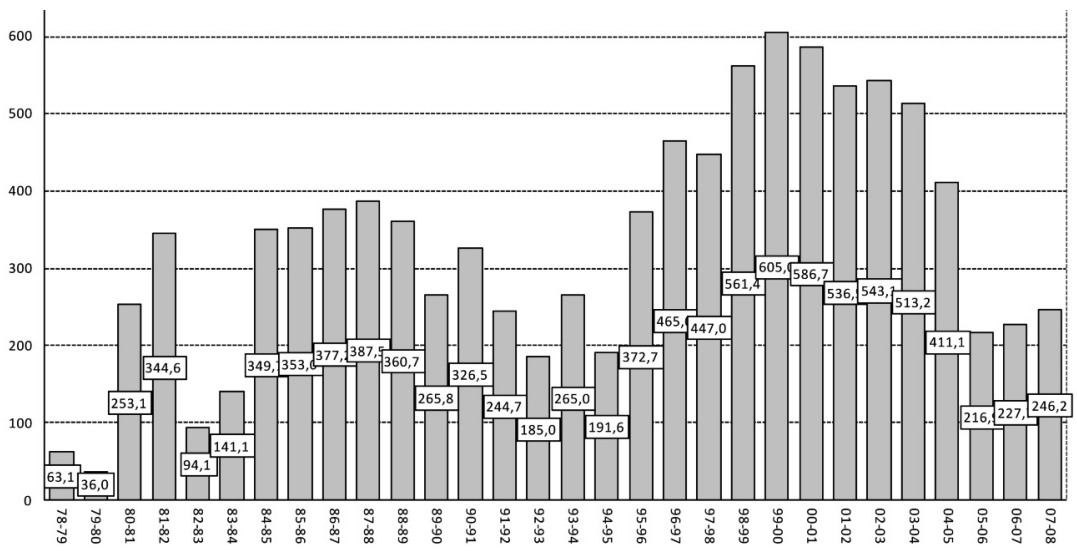

Fuente: elaboración propia a partir de datos aforados en los embalses del sistema Entrepeñas-Buendía.

FIGURA 5

REGRESIÓN LINEAL SIMPLE ENTRE LOS CAUDALES DERIVADOS POR EL TRASVASE TAJO-SEGURA (x) Y LAS APORTACIONES EN EL AFORO DE EL EMBOCADOR (y)

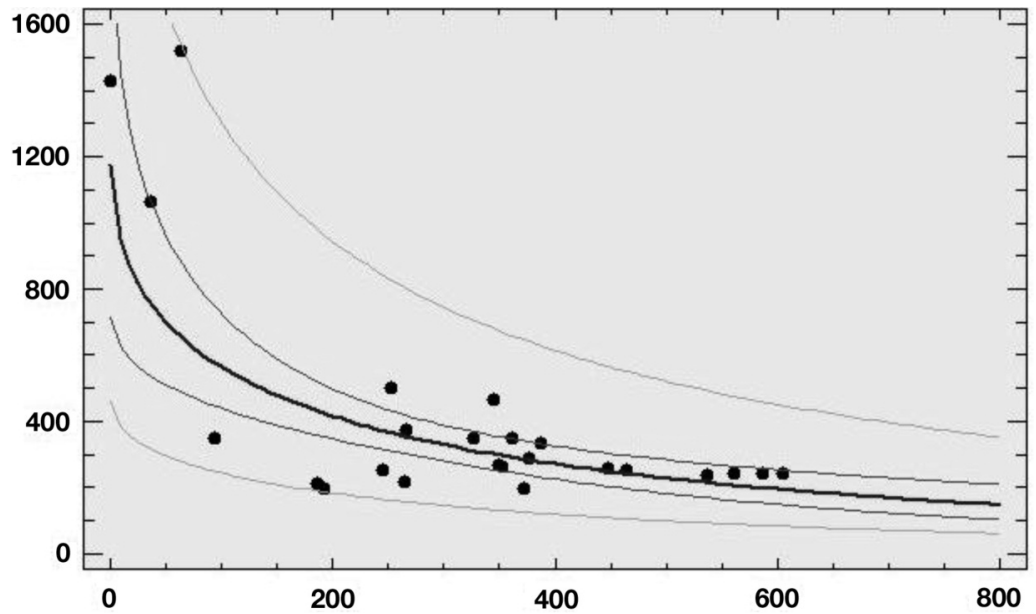

Fuente: elaboración propia. 
En las gráficas de la figuras 6 y 7 se aprecia claramente como tanto las aportaciones anuales $\left(\mathrm{hm}^{3}\right)$ como los caudales máximos instantáneos $\left(\mathrm{m}^{3} / \mathrm{s}\right)$ han disminuido bruscamente a partir del año hidrológico 1979-1980, el año en el comienzan a derivarse caudales del Tajo hacía el Levante ibérico. Los valores del caudal medio anual también manifiestan esa intensa alteración: los $36,95 \mathrm{~m}^{3} / \mathrm{s}( \pm 13,09 ; \mathrm{n}=25)$ del aforo de Aranjuez durante el periodo 1926$1929 / 1978-1979$ contrastan con los $17,33 \mathrm{~m}^{3} / \mathrm{s}$ del periodo 1979-1980/1984$1985( \pm 10,80 ; \mathrm{n}=5)$ y, especialmente, con los sólo $8,4 \mathrm{~m} 3 / \mathrm{s}$ del año hidrológico 1984-1985.

El impacto de las detracciones del trasvase sobre las aportaciones del Tajo es también apreciable aguas abajo de la Junta de los Ríos: los registros del aforo de Toledo muestran una correlación negativa moderada $\left(r_{s}=-0,392\right.$ : $\mathrm{p}<0,05, \mathrm{n}=26)$ con el volumen de agua trasvasado, considerando la misma serie 1978-1979/2002-2003.

En general, la regulación de la cuenca ha provocado una alteración importante de todo el tramo medio del Tajo-Jarama. El análisis de los datos procedentes de los aforos de El Embocador, Aranjuez, Puente Largo, Puente de Barcas y Toledo muestra que existen diferencias estadísticamente significativas entre las aportaciones reales y naturales registradas en estas estaciones de afo$\operatorname{ros}(z=0,4949 ; p=0,013 ; n=5)$.

La alteración del régimen hidrológico ha causado además la homogeneización de los caudales máximos instantáneos y, en consecuencia, la desaparición o minimización del suceso de avenidas extraordinarias, como puede observarse en la figura 9, donde se refleja la evolución de los caudales máximos instantáneos del aforo del río Jarama en el Puente Largo ( $n^{\circ}$ 3.175). En este aforo el descenso de los caudales máximos instantáneos ha sido notable tras la entrada el servicio del embalse de El Atazar $\left(462 \mathrm{hm}^{3}\right.$ ) en 1972, cuyo volumen representa el $40 \%$ del total embalsado en la subcuenca. El valor promedio correspondiente al periodo 1969-1972, previo al llenado del embalse, alcanzó un valor de $1.054,6 \mathrm{~m}^{3} / \mathrm{s}$, muy superior a los $293,14 \mathrm{~m}^{3} / \mathrm{s}$ del periodo $1974-2007$, valor que representa sólo un $27,8 \%$ del primero. En realidad, tras la entrada en funcionamiento del embalse de El Atazar, las únicas avenidas que han sucedido en el Jarama y también en el Tajo aguas abajo de la Junta de los Ríos desde la década de 1980 han estado causadas por el desembalse brusco de esta presa debido a la inadecuada gestión del volumen de resguardo, como sucedió en varias ocasiones en la década de 1990.

El efecto más patente de esta intensa alteración ha sido la disminución de las aportaciones anuales y la virtual desaparición del riesgo de avenidas, también la homogenización de los caudales estacionales. Precisamente, la ocupa- 


\section{FIGURA 6}

VARIACIÓN DE LAS APORTACIONES ANUALES (HM³) EN LOS AFOROS DE ARANJUEZ (No 3001) (AÑOS 1920-1921/1978-1979) Y EL EMBOCADOR ( No 3258) (AÑOS 1978-79/2001-2002)

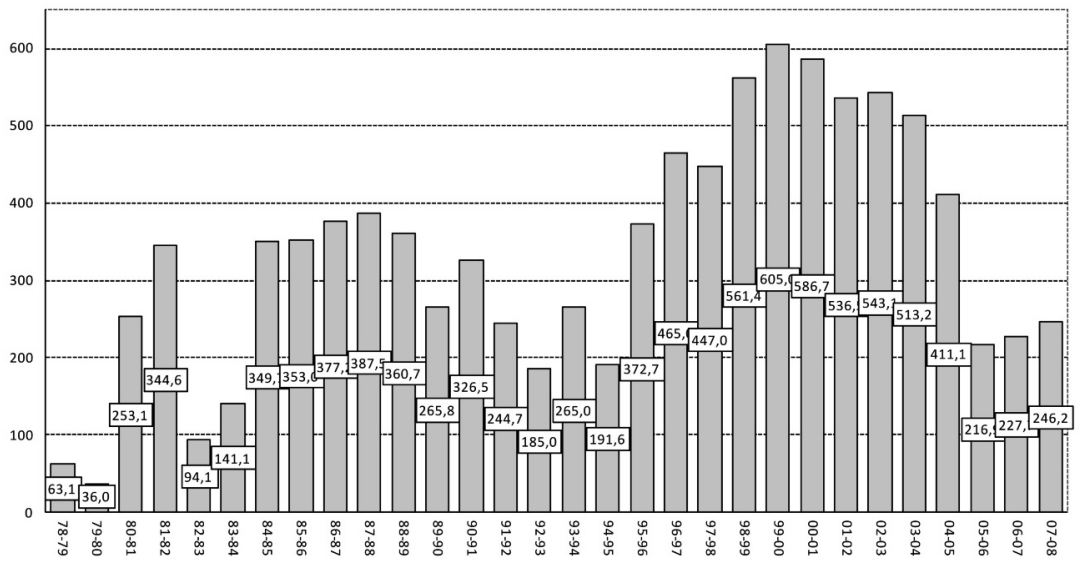

Fuente: elaboración propia a partir de datos aforados en los embalses del sistema Entrepeñas-Buendía.

FIGURA 7

EVOLUCIÓN DE LOS CAUDALES MÁXIMOS INSTANTÁNEOS (QCI) EN M³/S EN LOS AFOROS DE ARANJUEZ (No 3001) (AÑOS 1920-1921/1978-1979) Y EL EMBOCADOR (No 3258) (AÑOS 1978-1979/2001-2002

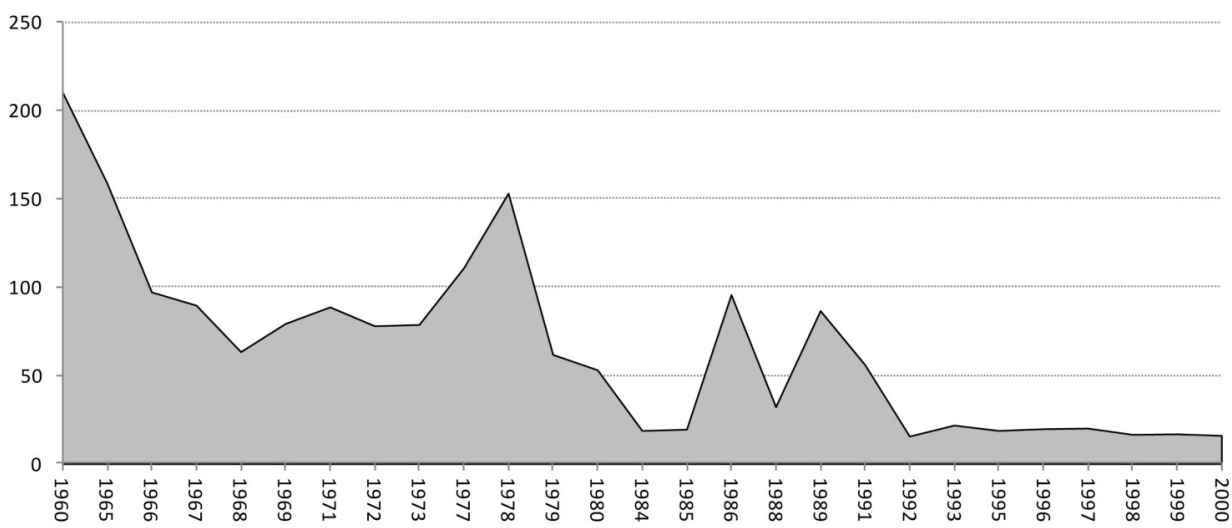

Fuente: elaboración propia a partir de datos aforados en los embalses del sistema Entrepeñas-Buendía. 
FIGURA 8

EVOLUCIÓN DE LAS APORTACIONES ANUALES (EN HM3) EN LA ESTACIÓN DE AFORO DEL PUENTE LARGO (No 3.175) EN EL PERIODO 1969-1970/2007-2008

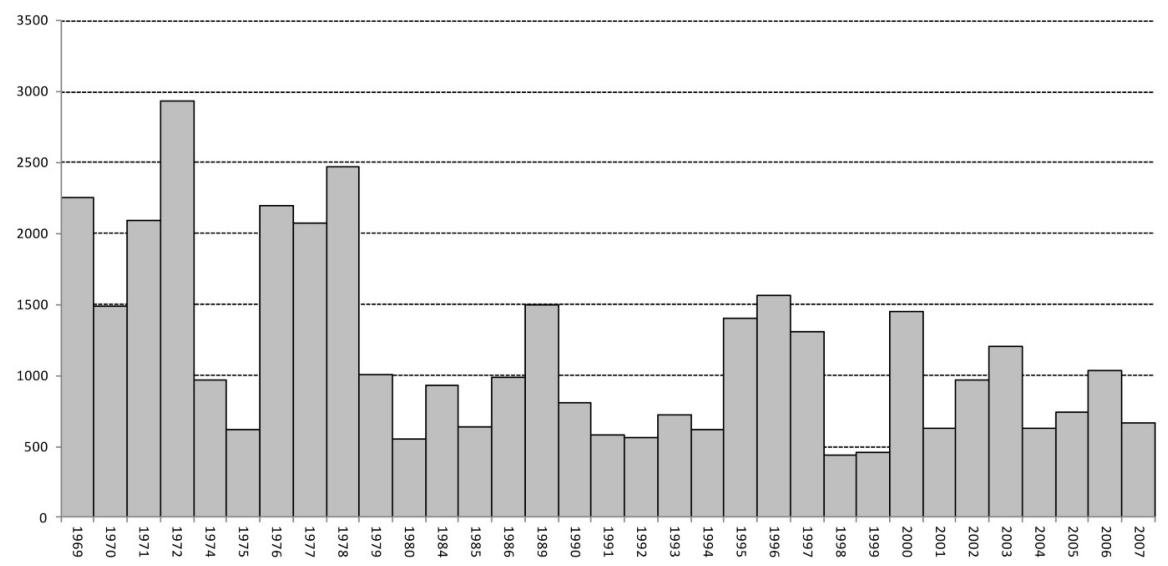

Fuente: elaboración propia a partir de datos aforados en los embalses del sistema Entrepeñas-Buendía.

FIGURA 9

EVOLUCIÓN DEL CAUDAL MÁXIMO INSTANTÁNEO QCI $\left(\mathrm{M}^{3} / S\right)$

EN LA ESTACIÓN DE AFORO DEL PUENTE LARGO (No 3.175)

EN EL PERIODO 1969-1970/2007-2008

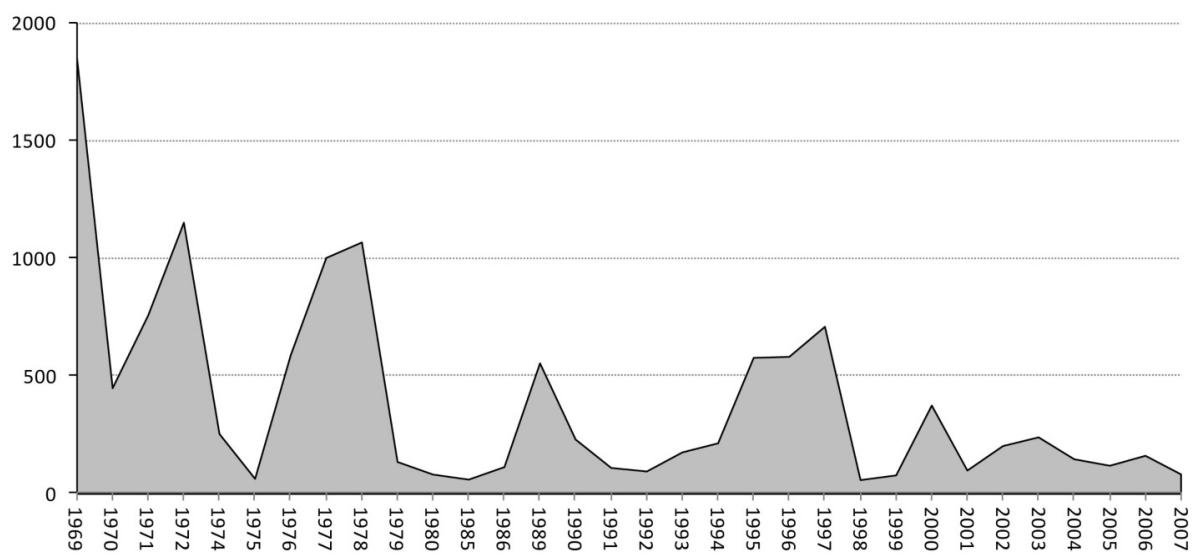

Fuente: elaboración propia a partir de datos aforados en los embalses del sistema Entrepeñas-Buendía.

Estudios Geográficos, Vol. LXXIV, 275, pp. 495-522, julio-diciembre 2013

ISSN: 0014-1496, eISSN: 1988-8546, doi: 10.3989/estgeogr.201318 
ción extensiva de la llanura de inundación del Tajo-Jarama posterior a 1950 está estrechamente relacionada con este suceso, de la misma forma que la reducción de los bosques, matorrales y praderas aluviales a partir de esa fecha se vincula a la alteración del régimen fluvial. La disminución de estos espacios tomando datos de los años 1880, 1936, 1974, 1996 y 2000, muestra una correlación negativa muy fuerte, casi perfecta, con el incremento del volumen regulado $\left(r_{s}=-0,997 ; \mathrm{p}<0,05 ; \mathrm{n}=5\right)$.

\section{LA FORMACIÓN DE LA PROPIEDAD ACTUAL Y SU RELACIÓN CON LA DINÁMICA FLUVIAL}

Hasta el desarrollo del proceso desamortizador en el último cuarto del siglo XIX la totalidad del término de Aranjuez perteneció a la corona. La venta de los bienes del patrimonio real dio lugar a la aparición de un conjunto de grandes propietarios que formaron entonces sus predios principalmente sobre tierras de bosque y en menor medida de labor del Real Sitio. Se enajenaron los pagos que hoy forman las grandes fincas de La Flamenca, Las Infantas y Castillejos, aguas abajo de Aranjuez, además de otras situadas al sur del ámbito de estudio (Utanda, 1980). En el sector de lo que hoy son las Huertas Históricas, localizadas aguas arriba de la desembocadura del río Jarama, la venta de bienes desamortizados afectó principalmente al paraje de Picotajo, donde todas las parcelas fueron vendidas a particulares (Terán, 1949); si bien, la extensión de estos predios, situados en el corazón del Real Sitio, fue considerablemente menor que la de las grandes fincas gestadas tras la venta, localizadas aguas abajo de la Junta de los Ríos, y la fragmentación de la propiedad fue notable. Hubo tierras que no tuvieron comprador y que revirtieron a Patrimonio Nacional. El Catastro de 1910-1911 identifica como propiedades públicas la Dehesa de Sotomayor, el Soto del Rebollo y el de Legamarejo, los jardines de la Isla y de El Príncipe, las Doce Calles y otras huertas menores diseminadas por la vega.

Tomando los datos brutos considerados por Utanda (1980), se advierte que del conjunto de terrenos subastados y vendidos (10.327,65 ha) en el término municipal de Aranjuez sobre las antiguas tierras del Bosque y Real Sitio, sólo dos grandes fincas (dos quintos del pago de Villamejor y la totalidad de La Flamenca más las adiciones a ésta de Las Infantas y Requena), ambas situadas aguas abajo de la Junta de los Ríos, supusieron en origen el 43,32\% del total. De ellas, la propiedad de La Flamenca, que agrega entre 1872 y 1890 parte de las citadas fincas de la Dehesa de Las Infantas y la Vega de Requena, representa el $28,71 \%$ (2.965 ha) del total enajenado. Las otras grandes propiedades existentes hasta finales de los años 80 del siglo xx (Casa Serranos, 1.501,66 
ha; Casa del Cerro, 855,09 ha; Valdepastores, 757,02 ha) están igualmente situadas aguas abajo de la Junta de los Ríos o en la vega del Jarama (Mata y Rodríguez, 1987). Es decir, excepción hecha de la gran finca de Sotomayor (1.192,93 ha), las cinco grandes propiedades de Aranjuez se localizan en el Tajo aguas abajo de la desembocadura del Jarama o en la vega y vertientes bajas de este último río (Casa del Cerro), sobre tierras de vega, terrazas media y tierras de aljezar. Las 7.587,33 ha de estas cinco grandes propiedades representaban entonces el $73,47 \%$ de los bienes vendidos.

Por el contrario, la mayor parte de las pequeñas propiedades formadas tras la Desamortización —y que aún hoy perviven en gran medida - se localizan en la vega del Tajo aguas arriba de la Junta de los Ríos, sobre terrenos de gran calidad agrológica, bien abastecidos por las infraestructuras de riego vinculadas al sistema de canales, caces y acequias derivados de los azudes de Valdajos y El Embocador. Prácticamente todas las tierras subastadas de este ámbito fueron ofrecidas como suertes o tranzones de reducidas dimensiones.

Existe por tanto una estrecha relación entre la localización de la gran propiedad y la posición de estas fincas. Así, retomando el caso ya señalado de La Flamenca, sólo una de las 250 fincas ofertadas ( $0,4 \%$ del total de fincas) representó el 17,22\% de la superficie vendida. Si se consideran además junto con la anterior los dos quintos de Villamejor, estas tres fincas (1,2\% de las subastadas) representaron el 33,6\% de la superficie total.

El parcelario de la vega de Aranjuez muestra, como la propiedad, dos ámbitos bien diferenciados, coincidentes con los dos grandes sectores paisajísticos identificados en las tierras que hasta el siglo XIX constituyeron el Real Sitio. Se reconoce una extensa zona que ocupa el área de propiedades fundamentalmente públicas y su entorno inmediato (entorno de Aranjuez aguas arriba de la Junta de los Ríos), donde el $60 \%$ de las parcelas poseen una extensión comprendida entre 1 y 5 ha. En este ámbito conviven pequeñas y medias propiedades privadas ( $<50 \mathrm{ha})$ con grandes propiedades públicas. En la vega del Jarama y en la del Tajo aguas abajo del curso anterior, el segundo ámbito reconocido, la extensión de las parcelas es mayor, siendo en más de un $50 \%$ de los casos superior a 50 ha y con frecuencia mayores de 100 ha. A finales del siglo xx, 22 de los 402 propietarios rústicos identificados (5,4\%) en Aranjuez poseían parcelas de extensión superior a 150 ha, que globalmente representaban más del 75\% del territorio del término municipal (Mata y Rodríguez, 1987).

Esta particular distribución de la tierra y organización de la estructura de la propiedad ha tenido importantes repercusiones paisajísticas. En efecto, los dos grandes sectores paisajísticos de las vegas del Tajo en Aranjuez se corresponden con los dos grandes sectores fundiarios, hidrológicos, parcelarios e 
históricos: se identifica un paisaje geométricamente ordenado situado en torno a la villa, el embrión del en otro tiempo extenso Real Sitio, integrado en su mayor parte en lo que es en la actualidad el «Paisaje Cultural» reconocido por la UNESCO, de propiedad dominantemente pública y parcelas de tamaño pequeño o medio. Aguas abajo de la Junta de los Ríos se identifica otro conjunto, de grandes propiedades, formado por la desmembración de los bienes de la corona, homogéneo, de parcelas más extensas, posición marginal respecto al núcleo e histórica vocación pecuaria, aún visible como sucede en Las Infantas, asiento de una importante ganadería extensiva (figura 10).

Las fincas enajenadas se sitúan mayoritariamente en la vega del Jarama y en la vega del Tajo aguas abajo de la confluencia de ambos cursos, fundamentalmente

\section{FIGURA 10}

ARRIBA A LA IZQUIERDA EXPLOTACIÓN GANADERA EN LAS INFANTAS Y, A LA DERECHA, VEGA DEL TAJO EN LAS INFANTAS-CASTILLEJOS. ABAJO A LA IZQUIERDA AZUD DE EL EMBOCADOR; A LA DERECHA, TRAMO BAJO DEL RÍO JARAMA EN EL DESAGÜE DE LA COLA ALTA DEL CANAL DE LA AZUDA

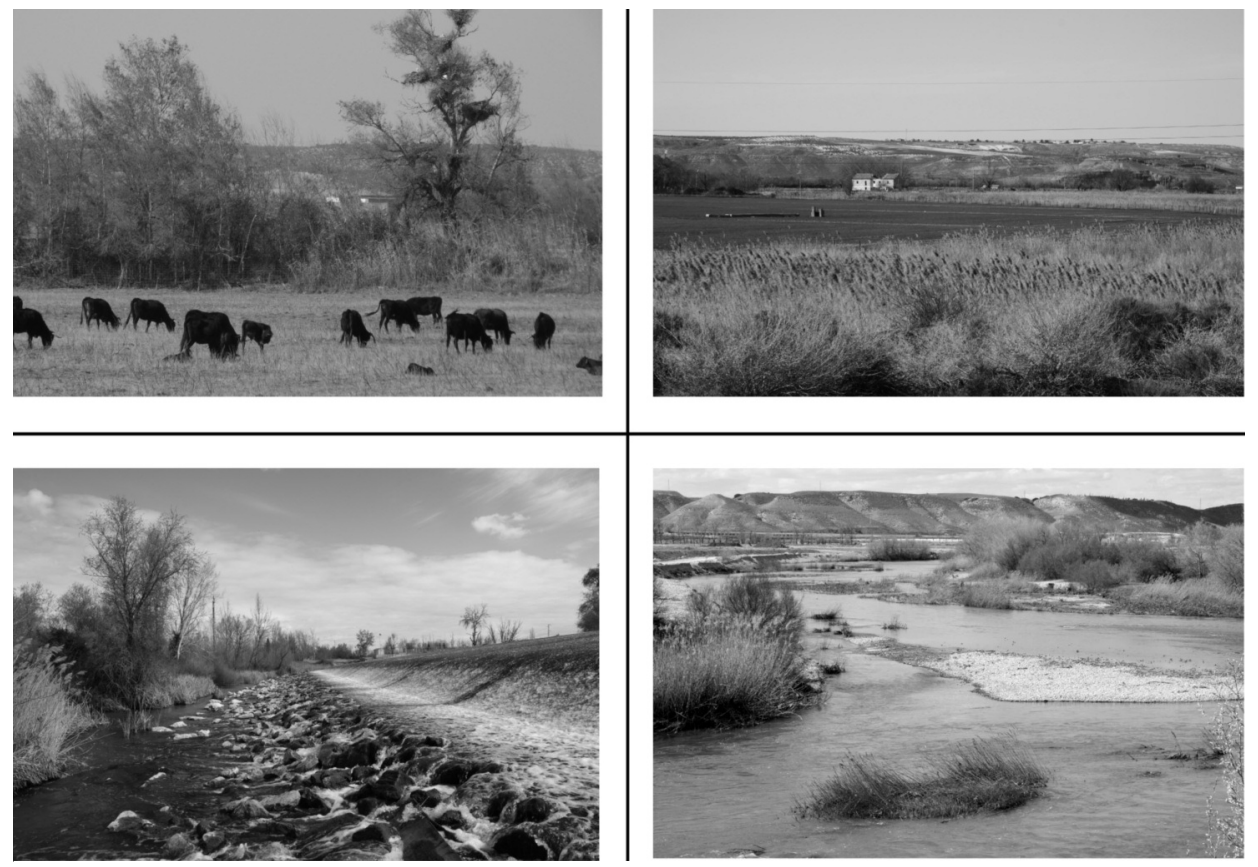

Fuente: elaboración propia. 
debido al menor valor agrícola y patrimonial de este espacio casi periférico, localizado en el extremo del valioso paisaje secularmente ordenado de jardines y huertas históricas. A diferencia de la vega del Tajo aguas arriba de la Junta de los Ríos, la del Tajo aguas abajo de este punto y la del Jarama se desarrollan sobre una llanura aluvial afectada con mayor frecuencia e intensidad por ciclos de aguas altas en las que los canales han migrado con gran frecuencia (figura 12).

Las referencias históricas a las crecidas del Tajo y del Jarama son muy frecuentes en textos históricos. Sobre el tramo bajo del río Jarama, López y Malta (1868) señala lo siguiente:

El Soto del Xembleque lindando con la dehesa del Redondillo y la de Sotogordo que siendo de la villa de Seseña dejó á este lado una fuerte crecida del Jarama, se trató de comprar a aquel pueblo en 1581 [...]. El 1633 otra nueva avenida dejó á este lado la mitad del Soto del Gasco y otro lado del Soto de Xembleque perteneciente a Seseña.

Las tierras irrigadas del Real Sitio, las más productivas, beneficiadas por el agua de la Real Acequia del Tajo y del conjunto de canales derivados de la presa del Embocador se situaban principalmente aguas arriba de la Junta de los Ríos en una zona de mayor estabilidad. La zona regable del Canal de las Aves alcanzaba a finales del siglo xIx el arroyo de La Cavina (López Gómez, 1988), pero las zonas adecuadas para el riego localizadas aguas abajo del Jarama se circunscribían a las pocas tierras aptas existentes en ese ámbito, elevadas sobre la extensa llanura de inundación en los cuarteles de La Flamenca y de Las Infantas, como puede observarse en la cartografía histórica de la primera mitad del siglo XIX.

No pasaron tampoco inadvertidas las avenidas del Tajo para Farinelli, mencionadas en el segundo libro de Fiestas Reales (1758):

Las frecuentes avenidas que anualmente se experimentan en el Río Tajo le inutilizan de modo que es forzoso estarle continuamente limpiando; por esta razón, y para el manejo de las fangadas, vienen todos los años por los meses de octubre o noviembre del Departamento de Marina de Cartagena 15 hombres de mar [...].

Las grandes fincas enajenadas en el proceso desamortizador han ido fragmentándose durante los últimos 150 años, debido a las segregaciones por herencia y a las ventas que, en algunos casos, se han ido realizando (Lacasta, 2005). Sin embargo, su representatividad es aún hoy suficientemente significativa como para influir de forma determinante en el paisaje de vega de Aranjuez. La singularidad de la organización territorial de la vega de Aranjuez se hace patente al compararla con las de otras vegas ocupadas por huertas históricas, como la de Colmenar de Oreja o la del Tajuña donde la fragmentación 
parcelaria y la pequeña propiedad son un rasgo distintivo del paisaje de regadío (Mata Olmo y Mato, 2010).

Las características originales de esta vega son por tanto consecuencia de la hidrodinámica activa del río Tajo aguas abajo de la recepción del Jarama (Molina, 1998). Como puede observarse en la figura 12, la movilidad del canal del Tajo ha sido históricamente más intensa aguas abajo de la Junta de los Ríos; además, la amplitud de la llanura de inundación de este sector de la vega, y en consecuencia la extensión de la zona inundable, de riesgo, mayor. La menor movilidad del canal aguas arriba del Jarama favoreció por tanto la ocupación de este sector de la vega, protegida además por algunas notables intervenciones como la canalización de la ribera del Tajo en la mayor parte del embrión del Real Sitio, como señala Álvarez de Quindós (1993 [1804]):

por Real Orden de 3 de octubre de 1772 se empezó á formar este del Príncipe [...]. Para defensa de las aguas del Tajo y sus crecidas se le hizo un fuerte murallón y pretil de piedra que se extiende por todo él.

En 1804 las obras de los Jardines de El Príncipe ya estaban terminadas, así es que la canalización debe haber sido realizada entre 1775, según se desprende del análisis de la cartografía existente, y esa fecha.

\section{FIGURA 11}

\section{TOPOGRAFÍA DEL REAL SITIO EN 1775}

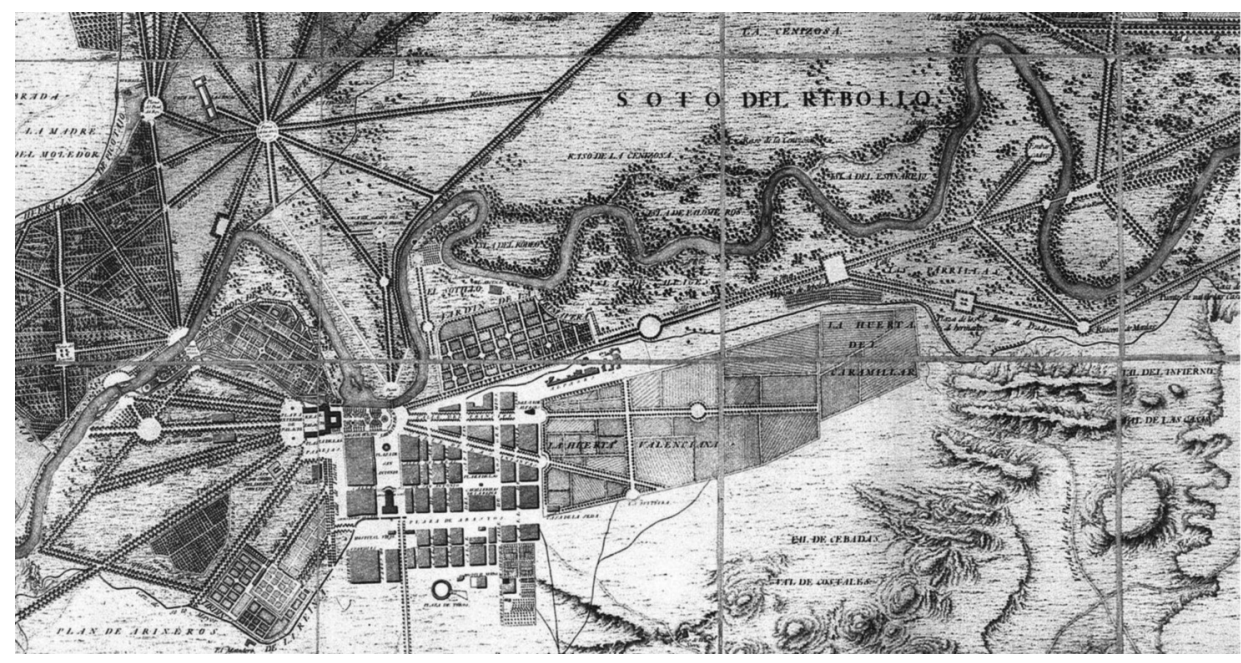

Fuente: Domingo Aguirre, capitán de Infantería de los Reg. P. y F. año MDCCLXXV. 
FIGURA 12

MOVILIDAD DEL CANAL DEL TAJO-JARAMA EN 1865 Y 1880
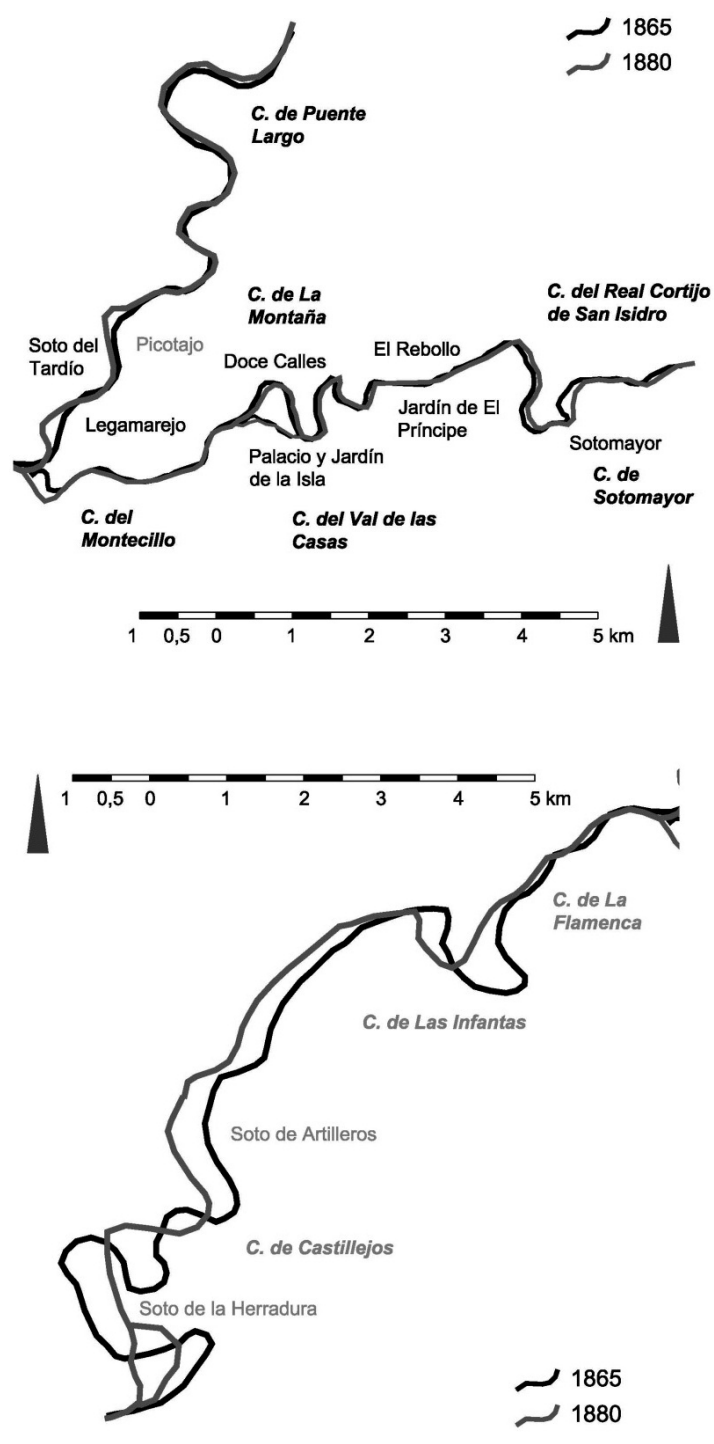

Nota: se indican los cuarteles y fincas más representativas de Aranjuez aguas arriba (izquierda) y aguas abajo (derecha) de la Junta de Los Ríos. En letra gris, los enajenados durante el proceso desamortizador.

Fuente: elaboración propia.

Estudios Geográficos, Vol. LXXIV, 275, pp. 495-522, julio-diciembre 2013

ISSN: 0014-1496, eISSN: 1988-8546, doi: 10.3989/estgeogr.201318 
La ribera del Tajo aguas arriba de la Junta de los Ríos fue también objeto de un buen número de intervenciones en las márgenes, realizadas para evitar el desbordamiento del río en periodos de aguas altas ya en el siglo XVI, como sucedió en el entorno de la calle Alpajés y el Soto del Rebollo:

El dique grande que se hizo para defensa de la calle de Alpajés ha servido mucho [...] donde hacía el daño han echado estas crecientes mucho légamo y levantándolo de manera que parece se asegurado el daño de la dicha calle y se entiende que todas las crecientes que vienieren iran siempre dejando allí legamo con que quedar a seguro y los diques que se hicieron en las torronteras para recibir el agua y defender la dicha calle están muy buenos y han resistido bien y parece conviene alargarlos algo mas lo cual se hará a su tiempo Archivo General de Simancas, Casas y Sitios Reales, leg. 251.2, fol. 30 c. 1561 (citado por Luengo, 2008).

En la actualidad, los cambios en el trazado de los cauces son mínimos, pudiendo considerarse que han perdido su movilidad después de los años 70 del siglo xx, debido a la intensa regulación de la cuenca.

\section{CARACTERÍSTICAS, DINÁMICA Y EVOLUCIÓN DE LOS ESPACIOS NATURALES Y SEMINATURALES DE LA LLANURA DE INUNDACIÓN}

La inestabilidad del cauce (figura 12), especialmente del tramo situado aguas abajo de la desembocadura del Jarama, explica por tanto la localización de la gran propiedad en este espacio pero también es uno de los factores que han influido en la conservación de los mejores y más extensos sotos de todo el ámbito hasta las primeras desamortizaciones (figuras 13) e, incluso, hasta el inicio de la regulación del sistema Tajo-Jarama en los años 50 del siglo xx. Conviene precisar que, de acuerdo con el Diccionario de la Real Academia, el término 'soto' se aplica no sólo a los espacios arbolados; hace referencia también a los grandes arbustedos de la vega y de la orilla aluvial, de muy variable densidad, formados en la zona de estudio por masas de Tamarix gallica y Tamarix africana, a veces con intrincados matorrales de Atriplex halimus. También a las praderas mesófilas de Elymus pungens y Brachypodium phoenicoides y a las praderas-juncales de Juncus acutus, Scirpoides holoschoenus y otras especies que con frecuencia, forman complejos mosaicos naturales o seminaturales con arboledas y arbustedos, como aún se observa en algunos enclaves de Las Infantas, entre otros ámbitos.

En efecto, existe una correlación positiva moderada entre la disminución de la longitud de los cursos en el periodo 1830-1999 y la reducción de la su- 
perficie forestada $\left(r_{\mathrm{s}}=0,4062, \mathrm{p}<0,005, \mathrm{n}=5\right)$ en las riberas de Aranjuez. Si bien, las causas que explican esta progresiva reducción de los sotos del TajoJarama son al menos dos y sus implicaciones paisajísticas bien diferentes. Así, cabe señalar como causas principales el desarrollo del proceso desamortizador en el periodo 1865-1936 y la alteración del comportamiento hidrológico del sistema Tajo-Jarama en el periodo posterior a 1936 (1975-1999). Anteriormente, la extensión de los sotos del Tajo fue tan notable que, como señala Arroyo (2006) citando las referencias de Cabanes (1829) sobre el reconocimiento de Antonelli, una de las tres dificultades especiales que hacía compleja la navegación en este río eran «los sotos que embarazan el sirgar».

La superficie de los sotos ocupaba una extensión de 1.852 ha en 1865. En 1880 la superficie de estos ámbitos habían descendido a 587,6 ha, valor que supone en términos porcentuales una disminución del 68,49\% respecto a la extensión alcanzada tan sólo 15 años antes. Este acusado retroceso, que bien recuerda a algunas lamentables deforestaciones tropicales de la actualidad, es enteramente atribuible a la corta de arboledas y tarayales y a la rotura de muchas tierras de pasto, hasta entonces parte integrante del Bosque de Aranjuez. La enajenación de buena parte de las vegas de Aranjuez, que hasta entonces habían pertenecido a la Corona, propició un rápido retroceso de los bosques fluviales (figura 13) y una creciente simplificación del paisaje de las llanuras aluviales, al ampliarse y uniformizarse los cultivos en detrimento de otros aprovechamientos consuetudinarios (López y Mateu, 2009). Sin embargo, la plena ocupación agrícola de la llanura de inundación no se hizo efectiva hasta la regulación de los ríos Tajo y Jarama. Prueba de ello es la evolución de la superficie forestal de este sector de la plana aluvial entre 1880 y 1936: en ese periodo de 56 años, la pérdida de sotos (38 ha) representa sólo un 4,6\% respecto del valor registrado en 1880 .

La enajenación de grandes fincas provocó sin duda cambios significativos en el uso de la llanura aluvial, desde entonces, paulatinamente dirigido hacia un modelo agrícola productivista dependiente de las exigencias de mercado. Estos cambios, sin embargo, no se produjeron de manera inmediata en las fincas que mantuvieron su titularidad pública, aunque las posteriores cesiones y alquileres de huertas y haciendas por parte de Patrimonio Nacional provocaron cambios más o menos intensos según los casos (Aníbarro, 2010). De este modo, la evolución del paisaje de vega en el ámbito de estudio durante la segunda mitad del siglo XIX y todo el siglo Xx se caracteriza por una notable dualidad: por una parte, un proceso acelerado de cambio en el paisaje de la vega situado aguas abajo de la Junta de los Ríos; por otra, una cierta fosilización en la dinámica del paisaje de la vega del Tajo aguas arriba de la Junta. 
Las pérdidas de sotos observadas en el periodo 1880-1936 son atribuibles a la ocupación de los pocos ámbitos de la llanura de inundación cuya transformación aún era rentable, por ser áreas de inundación esporádica en un contexto hidrológico caracterizado aún por su comportamiento casi natural. Sin embargo, la superficie observada 39 años después, en 1975 (139 ha), supone un descenso del 74,73\% respecto al valor de 1936. En 1999, la extensión de los sotos del Tajo-Jarama alcanzaba la exigua y triste extensión de 86 ha, un 38,13\% de la extensión ocupada en 1975 y tan sólo 4,64\% de la superficie ocupada en 1865 (figura 13). En 1995, la extensión de la superficie arbolada de la ribera del Jarama representaba tan sólo un 1,38\% de la superficie potencial y, en su mayor parte, los escasos conjuntos forestales existentes a mediados de los años 90 del siglo xx estaban integrados por tayarales de Tamarix gallica desarrollados sobre el dominio potencial de alamedas de Populus alba (Molina, 2003).

Estas notables pérdidas son el resultado de la alteración del comportamiento hidrológico del sistema Tajo-Jarama a partir de la intensa regulación de la cuenca posterior a 1950, que se manifiestan también la estabilización de los canales de bankfull. Uno de los hitos de esta profunda alteración de la naturalidad de los ríos es la construcción del complejo hidráulico EntrepeñasBuendía, que entró en servicio en 1957. Estos dos grandes embalses de volumen hiperanual no sólo eliminaron las crecidas extraordinarios del Tajo, también aseguraron un caudal de estiaje suficiente para mantener los riegos de toda la vega. La ocupación de los sectores más inestables de la plana aluvial se completó con el control casi total de la subcuenca del Jarama, tras la construcción de la presa de El Atazar en el río Lozoya en 1972 (Molina y Berrocal, 2006). Este conjunto de actuaciones convirtieron en «terra firma» las zonas más inestables de la llanura de inundación, desde entonces tierra agrícola de gran valor debido a la eliminación virtual del riesgo de inundación.

En la actualidad, la pervivencia de espacios arbolados de cierta extensión está vinculada a factores fundiarios y, secundariamente, a la existencia de enclaves de gran inestabilidad ambiental, no aptos para su puesta en cultivo, cuya existencia no se debe a factores naturales, sino a la existencia de pequeñas obras hidráulicas (Molina y Berrocal, 2006). En efecto, el tramo mejor forestado de la ribera del Tajo se localiza aguas arriba de la confluencia de este curso con el Jarama, precisamente el más alterado, tanto desde un punto de vista hidrológico como hidráulico. Este aparente contrasentido se vincula a factores no naturales relacionados con el tipo de propiedad de la tierra. Como ya se ha explicado, el entorno de Aranjuez aguas arriba del río Jarama forma parte de las propiedades del Patrimonio del Estado que integran el Real Sitio, en la actualidad una pequeña fracción no enajenada en la Desamortización Ci- 


\section{FIGURA 13}

EVOLUCIÓN DE LOS SOTOS DE LA RIBERA DEL TAJO-JARAMA EN ARANJUEZ EN 1865, 1880, 1936, 1975 Y 1999

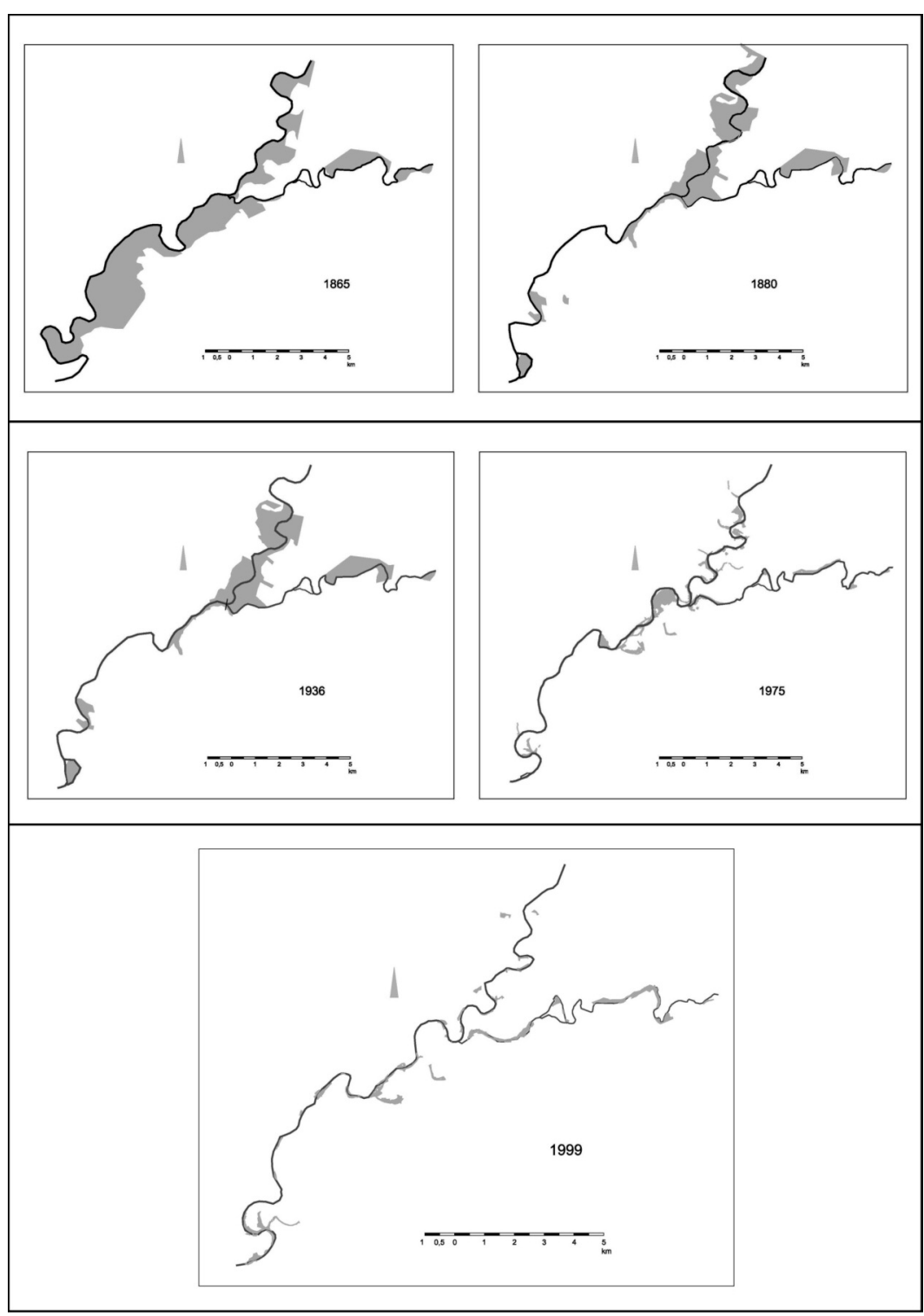

Fuente: elaboración propia.

Estudios Geográficos, Vol. LXXIV, 275, pp. 495-522, julio-diciembre 2013 ISSN: 0014-1496, eISSN: 1988-8546, doi: 10.3989/estgeogr.201318 
vil del que fuera el extenso Bosque y Real Sitio de Aranjuez. El uso del suelo de esta gran propiedad pública, poco intensivo, ha permitido que aún se conserven extensas masas forestadas en posiciones que, en otras áreas de la vega, ya habrían favorecido su transformación en campos de cultivo, como sucedió en el meandro posterior a la Junta de los Ríos a finales del los años 80 del siglo xx en la Finca de La Flamenca (Molina, 2003).

\section{CONCLUSIÓN}

El paisaje de la vega del Tajo es, en la actualidad, el resultado de un complejo proceso histórico en gran medida condicionado por la evolución de la propiedad de la tierra tras el inicio del proceso desamortizador, cuyas ventas afectaron principalmente a las tierras del Real Sitio localizadas en la vega del Jarama y en la vega del Tajo aguas abajo de su confluencia con el anterior curso. Si, en origen, la intensidad y frecuencia de los ciclos de aguas altas, y en consecuencia la frecuencia de inundación de la vega, condicionó la oferta de tierras desamortizables, posteriormente los factores ligados a las características hidrodinámicas del sistema Tajo-Jarama han desempeñado un papel secundario en la evolución del paisaje aluvial.

La venta masiva de tierras aguas abajo de la confluencia Tajo-Jarama causó una rápida reducción de los bosques, matorrales y praderas aluviales. La superficie natural y seminatural del fondo de valle en 1880 ( 587 ha) había descendido un 68,5\% respecto a 1865 (1.852 ha). Sin embargo, la superficie ocupada en 1936 (550 ha) sólo había disminuido un 6,3\% respecto a la registrada en 1880. Hasta los años 70 del siglo xx, la mayor parte de la superficie de sotos, tarayales y praderas ( $>75 \%$ ) se localizaba aguas abajo de la confluencia Tajo-Jarama debido en gran medida a la inestabilidad de la zona más baja de la llanura de inundación, afectada reiteradamente por las potentes avenidas del Tajo, una vez unidas sus aguas al Jarama, el curso principal en términos hidrológicos, morfológicos y paisajísticos. Después de los años 70, los más extensos sotos de Aranjuez se localizan aguas arriba de la desembocadura del Jarama, protegidos por su ubicación en propiedades públicas colindantes a grandes espacios ajardinados, paseos arbolados o huertas históricas.

Las dos causas principales que han modificado el paisaje de Aranjuez desde la segunda mitad del siglo XIX (desamortización y alteración del comportamiento hidrológico del sistema fluvial) han tenido por tanto diferentes implicaciones territoriales, más allá de la reducción de los espacios naturales y seminaturales de la llanura de inundación. 
La desamortización de las tierras de la corona supuso la eliminación de extensos espacios forestados situados en la llanura de inundación e incluso en la primera terraza. Estas pérdidas provocaron sin duda una simplificación y una profunda transformación del paisaje de la vega aunque de menor alcance que el derivado de la degradación del comportamiento hidrológico de los ríos Tajo y Jarama, provocado por el desarrollo del Plan Nacional de Obras Hidráulicas posterior a 1950. La modificación de las características hidrológica e hidráulicas de estos cursos, observada en todos los ríos mediterráneos de España, modificó la potencialidad de la llanura de inundación debido a la disminución de la intensidad de los ciclos de aguas altas, al aumento de los periodos de retorno de las avenidas extraordinarias, a la minimización del efecto de las avenidas ordinarias y al acusado descenso de las aportaciones medias anuales. Las tierras que hasta los años 50 de siglo xx se inundaban con periodos de retorno de 5 años dejaron de hacerlo, convirtiéndose en áreas de gran interés agrario. La expansión de la frontera agrícola sobre los últimos sotos del Tajo-Jarama, sobre las 550 ha existentes en 1936, sólo fue posible una vez regulada la cuenca del Tajo-Jarama.

La desamortización provocó una profunda modificación del paisaje de las llanuras de inundación. Fue una degradación intensa aunque con posibilidad de recuperación, a diferencia de las alteraciones derivadas de la modificación del funcionamiento hidrológico de la cuenca, irreversibles debido a la pérdida de funcionalidad hidrológica de la llanura de inundación. En esta pérdida de funcionalidad ha influido de manera considerable el trasvase Tajo-Segura, cuyas derivaciones medias representan un $42,61 \%$ de las aportaciones observadas en régimen natural en el aforo de El Embocador $\left(1.305 \mathrm{hm}^{3}\right)$. El promedio trasvasado hasta la fecha ha sido de $556 \mathrm{hm}^{3} /$ año, cifra muy próxima a los 600 $\mathrm{hm}^{3}$ calculados como «excedentarios» en el primer anteproyecto de trasvase de 1967 (Ley 21/1971, de 19 de junio, sobre el aprovechamiento conjunto Tajo-Segura).

El descenso de la aportaciones naturales en la cuenca producido desde 1980, próximo al 50\% en la cabecera del Tajo, no ha supuesto modificación alguna del texto legal que regula el trasvase. Es previsible por tanto una alteración aún más profunda del régimen del río Tajo y, por ello, una acusada modificación del paisaje de Aranjuez debido al incremento de la aridez de la vega.

Fecha de recepción: 24/09/2012

Fecha de aceptación: 22/01/2013 


\section{BiBLIOGRAFÍA}

Allan, J. D. (1999): "El régimen natral de los ríos. Un paradigma para su conservación y restauración", en F. J. Martínez y P. Arrojo (coords): El agua a debate desde la Universidad: hacia una nueva cultura del agua: $1^{\text {er }}$ Congreso Ibérico sobre Gestión y Planificación de Aguas. Zaragoza, Institución Fernando El Católico, pp. 483-498.

Allan J. D. (2004): "Landscapes and riverscapes: the influence of land use on stream ecosystems". Annual Review of Ecology, Evolution and Systematics, 35, pp. 257-284.

Álvarez de Quindós, J. A. (1993 [1804]): Descripción histórica del Real Bosque y Casa de Aranjuez. Madrid, Edición facsimilar Ed. Doce Calles.

Anibarro, M. A. (2010): "La actividad agrícola en las huertas y sotos", en Plan de Gestión del Paisaje Cultural de Aranjuez. Análisis y iagnóstico. Informe inédito. Ayuntamiento de Aranjuez, Universidad Politécnica de Madrid.

Arroyo, F. (2006): "Marinas y riberas interiores: notas para una geografía histórica del Tajo en los siglos XVI y XVIII". Cuadernos de Geografía, 73-74, pp. 233-258.

Berrocal, A. B. y Molina, P. (2012): "Assessing the landscape value of public works: validation of the method in the lowlands of the middle section of the Tajo river (Spain)". Landscape Research (en prensa).

Broschi Farinelli, C. (1991 [1758]): Fiestas Reales. Madrid, edición facsímil del manuscrito original, Consorcio para la organización de Madrid Capital Europea de la Cultura 1992, Patrimonio Nacional, Turner libros.

Cabanes, F. (1829): Memoria que tiene por objeto manifestar la posibilidad de hacer navegable el río Tajo desde Aranjuez hasta el Atlántico. Madrid, Imp. Miguel de Burgos.

Cañada, R., Galán, E. y Fernández, F. (2010): "Situación actual y previsiones futuras de las disponibilidades hídricas de la Comunidad de Madrid y áreas circundantes", en F. Fernández, E. Galán y R. Cañada (eds.): Clima, ciudad y ecosistemas. Madrid, Publicaciones de la Asociación Española de Climatología, Serie A, 7, pp. 349-366.

De Miguel, J. C. y Segura, C. (coords.) (1998): Agua e ingenios hidráulicos en el valle del Tajo (De Estremera a Algodor entre los siglos XIII y XVIII). Madrid, Confede ración Hidrográfica del Tajo.

Décamps, H., Planty-Tabacchi, A. M. y Tabacchi, E. (1995): "Changes in the hydrological regime and invasions by plant species along riparian systems of the Adour River, France". Regulated Rivers: Research and Management, 11, pp. 23-34.

Décamps, H., Fortuné, M., Gazelle, F. y Pautou, G. (1988): "Historical influence of man on the riparian dynamics of a fluvial landscape". Landscape Ecology, 1, pp. 163-173.

Dynesius, M. y Nilsson, C. (1994): "Fragmentation and flow regulation of river systems in the northern third of the world". Science, 66, pp. 753-762.

Gallego, M. S. y Sánchez, M. A. (2006): "La destrucción ambiental del río Tajo: orígenes, procesos y consecuencias", en V Congreso Ibérico de Gestión y Planificación del Agua, 4-8 de diciembre de 2006, Faro, Portugal.

González, J. (1975): Repoblación de Castilla La Nueva. Madrid, Universidad Complutense de Madrid. 
González, M. A. y Lastra, I. de la (2007): La urbanización y su efecto en los ríos. Mesa de Trabajo, en Ministerio de Medio Ambiente y Universidad Politécnica de Madrid (ed.): Estrategia Nacional de Restauración de Ríos y Riberas, Madrid, julio de 2007. Disponible en: http:/www.magrama.gob.es/es/agua/publicaciones/urbanizacion_ efectos_en_rios_julio_2007_1_tcm7-27581.pdf (Fecha de consulta: 17/07/ 2013).

González del Tánago, M. (1999): "Las riberas, elementos clave del paisaje y en la gestión del agua", en F. J. Martínez y P. Arrojo (coords): El agua a debate desde la Universidad: hacia una nueva cultura del agua: $1^{\text {er }}$ Congreso Ibérico sobre Gestión y Planificación de Aguas. Zaragoza, Institución Fernando El Católico, pp. 499-512.

Jansson, R., Nilsson, Ch., Dynesius, M. y Andersson, E. (2000): "Effects of river regulation on river-margin vegetation: a comparison of eight boreal rivers". Ecological Applications, 10, pp. 203-224.

Johnson, W. C. (1998): "Adjustment of riparian vegetation to river regulation in the great plains, USA”. Wetlands, 18, pp. 608-618.

Lacasta, P. (2005): "El funcionamiento de la gran explotación y los valores del paisaje", en APGEO (ed.): X Colóquio Iberico de Geografia. 22-24 de Setembro de 2005, Universidade de Évora. Disponible en: http://www.apgeo.pt/index.php?section=130 (Fecha de consulta: 17/07/2013).

López Gómez, A. (1988): Antiguos riegos marginales de Aranjuez. Mares, azudas, minas y canales. Madrid, Real Academia de la Historia.

López y Malta, C. (1988 [1868]): Historia descriptiva del Real Sitio de Aranjuez escrita en 1868 sobre lo que escribió en 1804 D. Juan Álvarez de Quindós. Aranjuez, Doce Calles.

López, M. J. y Mateu, F. F. (2009): "Desamortización e intensificación agraria de riberas fluviales: la a vega de Aranjuez", en A. Romero Díaz, F. Belmonte Serrato, F. Alonso Sarria y F. López Bermúdez (coords.): Avances en estudios sobre desertificación: aportaciones al Congreso Internacional sobre Desertificación en memoria del profesor John B. Thornes, (Murcia, 2009). Murcia, Universidad de Murcia, pp. 701-704.

Luengo, A. (2008): Aranjuez. La construcción de un paisaje. Utopía y realidad. Madrid, Doce Calles, CSIC-Instituto de Estudios Madrileños.

Mata Olmo, R. y Mato Miguel, J. F. (2010): "Los regadíos históricos del Tajuña. Río Tajo", en J. Hermosilla (dir.): Los regadíos históricos españoles: paisajes culturales, paisajes sostenibles. Madrid, Ministerio de Medio Ambiente, Medio Rural y Marino, pp. 329-364.

Mata Olmo, R. y Rodríguez Chumillas, I. (1987): "Propiedad y explotación agrarias en el regadío de las 'vegas' de Madrid”. Agricultura y Sociedad, 42, pp. 149-180.

Molina, P. (1998): "Estudio del paisaje natural del sector centro-oriental de la Depresión del Tajo (Madrid-Toledo) y del sector central de la Depresión del Ebro (Navarra-Zaragoza). Análisis y comparación de sus estructuras y dinámicas". Tesis Doctoral, Universidad Autónoma de Madrid, Departamento de Geografía.

Molina, P. (2003): Análisis y comparación de la vegetación de las riberas de los ríos Ebro, Tajo y Jarama. Madrid, UAM Ediciones, Obra Social Cajamadrid.

Molina, P. y Berrocal, A. B. (2006): "Los efectos ambientales de la regulación de los cursos de la cabecera de la cuenca del Tajo: la reducción de los bosques aluviales 
del Tajo-Jarama", en Colegio de ingenieros de caminos, canales y puertos (ed.): III Congreso de Ingeniería Civil, territorio y Medio Ambiente. "Agua, diversidad e ingeniería”. Zaragoza, 25-27 octubre de 2006. Zaragoza, Colegio de ingenieros de caminos, canales y puertos.

Molina, P., Berrocal, A. B. y Barrasa, S. (2012): "La protección del paisaje fluvial y gestión del agua en la cuenca del Tajo (España)", en XVI Congreso de la Sociedad Mesoamerica para la Biología de la Conservación, Panamá (en prensa).

Molina, P., Sanz, C. y Mata, R. (2010): Los paisajes del Tajo. Madrid, Ministerio de Medio Ambiente, Medio Rural y Marino, Gobierno de España.

Naiman, R. J., Décamps, H. y Pollock, M. (1993): "The role of riparian corridors in maintaining regional biodiversity". Ecological Applications, 3, pp. 209-212.

Nilsson, C. y Berggren, K. (2000): "Alterations of Riparian Ecosystems Caused by River Regulation". BioScience, 50/9, pp.783-792.

Nilsson, C., Reidy, C. A., Dynesius, M. y Revenga C. (2005): "Fragmentation and flow regulation of the world's large river systems". Science, 308, pp. 405-408.

Nilsson, C., Jansson, R., Malmqvist, B. y Naiman, R. J. (2007): "Restoring riverine landscapes: the challenge of identifying priorities, reference states, and techniques". Ecology \& Society, 12/1, art.16.

Poff, N. L., Richter B. D., Arthington A.H. et al. (2010): "The ecological limits of hydrologic alteration (ELOHA): a new framework for developing regional environmental flow standards". Freshwater Biology, 55, pp. 147-170.

Petts, G., Roux, A. L. y Moller, H. (eds.) (1989): Historical Changes of Large Aluvial Rivers, Western Europe. Chichester, Wiley.

Poff, N. L. y Zimmerman J. K. H. (2010): "Ecological responses to altered flow regimes: a literature review to inform the science and management of environmental flows". Freshwater Biology, 55, pp. 194-205.

Sanz Hernando, A. (2008): "El jardín histórico: memoria esencial del paisaje cultural", en Centro de Estudios Históricos de Obras Públicas y Urbanismo (CEHOPU): Actas de $4^{\circ}$ Congreso Europeo sobre Investigación Arquitectónica y Urbana EURAU08 Paisaje Cultural. Madrid, Ministerio de Fomento.

Terán, M. (1949): "Huertas y jardines de Aranjuez". Revista de la Biblioteca, Archivo y Museo Municipal, 58, pp. 329-421.

Utanda, L. (1980): "Factores físicos y desamortización en la vega de Aranjuez". Estudios Geográficos, 41/158, pp. 69-87.

Yon, D. y Tendron, G. (1981): Alluvial forests of Europe. Nature and Environment Series No. 22. Strasbourg, Council of Europe.

\section{RESUMEN}

El paisaje de la vega del Tajo en Aranjuez es el resultado del efecto de la desamortización civil sobre el territorio que integraba hasta la segunda mitad del siglo xIx el Real Sitio. También es fruto de la alteración del sistema fluvial producida por la regulación 
de la cuenca posterior a 1950. Hasta 1880, la venta de bienes afectó mayoritariamente a las tierras situadas aguas abajo de la confluencia Tajo-Jarama y provocó la pérdida de muchos espacios forestales de uso eminentemente cinegético. Posteriormente, las aún extensas zonas naturales de la llanura de inundación en esta área, integradas en grandes fincas privadas surgidas tras la desamortización, se mantuvieron hasta finales de la década de 1960 debido a su frecuente inundación. A partir de esa fecha, la regulación de la cuenca permitió la ampliación de la frontera agrícola sobre las zonas más inestables, ocupadas hasta entonces por grandes sotos y praderas.

PAlABRAS ClaVE: paisaje fluvial; propiedad de la tierra; regulación fluvial; presas; embalses; bosques de ribera; río Tajo; río Jarama; Aranjuez.

\section{ABSTRACT}

The landscape of the alluvial plain of the Tagus river in Aranjuez is the result of the effects of civil disentailment of the territory which until the second half of the nineteenth century made up the Real Sitio (Royal Site). It is also the result of the alteration of the fluvial system produced by regulation of the river after 1950. In an initial phase until 1880, the sale of property had its main effecton land downstream from the Jarama-Tagus confluence, and caused the loss of many forest areas hitherto mostly used for hunting purposes. Later, the large remaining areas of natural floodplain in the area, part of large private estates which emerged after the disentailment of royal properties, continued to exist until the late 1960s due to their frequent flooding. From that date, regulation of the basin allowed for expansion of the agricultural zone into the previously unstable areas hitherto occupied by large alluvial forests and meadows.

KEY WORDS: fluvial landscape; land property; river regulation; dams; reservoirs; alluvial forest; Tagus rivers; Jarama river; Aranjuez.

\section{RÉSUMÉ}

Le paysage de la vallée du Tage en Aranjuez est le résultat des effets de la désamortissement civile du territoire qui a fait la seconde moitié du xixe siècle, le Site Royal. Il est également le résultat du système fluvial altéré produite par la régulation du bassin à partir de 1950. Jusqu'en 1880, la vente de biens à affecter en aval de la confluence des terres et de Jarama du Tage, a causé la perte de nombreuses zones forestières jusque-là éminemment guide de chasse. Plus tard, les zones encore de grandes plaines inondables naturelles dans ce domaine, une partie de grandes exploitations privées ont émergé après la désamortissement, est resté jusqu'à la fin de 1960 en raison de sa inondations fréquentes. Depuis cette date, la régulation du bassin a permis l'expansion de la frontière agricole sur les zones instables, jusque-là occupés par des grands forêts alluviales et de prairies.

Mots CLÉs: paysage fluvial; propriété de la terre; regulation fluvial; barrages; reservoirs; forêts riveraines; Tage; Jarama; Aranjuez. 